\title{
Rutin Ofis Hizmetlerinde İnovasyon Tasarımı
}

\section{$\ddot{\mathbf{O} z}$}

Inovasyon bir disiplin konusu haline gelmektedir. Bu çalışmanın amacı, çalışanları ezberden ve bilgi yükünden kurtarmak ve tasarım düşüncesi yoluyla adım adım inovasyonda güven kazanmalarına yardımcı olmaktır. Çoğu çalışan, özellikle rutin ofis hizmetlerinde olanlar, kendilerini yenilikçiliğin bir parçası olarak görmemektedirler. Bu makale, çalışanların inovasyon sürecine aktif katılımını güçlendirme yöntemini göstermeyi amaçlamaktadır. İnovasyona uzak gibi görünen, statik, monoton bir arka plan ofis hizmeti sunan birimler dahi inovasyonun kaynağı olmaktalar. Bu makalede bir tekstil firmasında böyle bir ofis hizmeti sunan ithalat satın alma (buy-in) biriminde gerçekleştirilen inovasyon çalışması örnek olarak gösterilmektedir. Tasarım düşüncesinde aşamalar; paydaşları dinleme, çıkarımları gruplama, fikirleri üretme, prototipler kurgulama ve yine paydaşlardan geri dönüşüm alma olarak ilerlemektedir. Yaratıcı güven, tasarım düşüncesi inovasyon metodolojilerini yavaş ve kararlı eylemlerle uygulayarak elde edilmektedir.

Anahtar Kelimeler: Aktif katılım, inovasyon, tasarım düşüncesi, rutin işler.

\section{Designing Innovation at Routine Office Services}

\begin{abstract}
Innovation is becoming a discipline. The aim of this study is to release employees from memorization and information burden and to help them gain creative confidence step by step through design thinking. This article aims to strengthen the active participation of employees in the innovation process. Most employees, especially those are in routine office services, do not see themselves as a part of innovation. However, even units that offer a static, monotonous background office service that seem distant to innovation can be the source of innovation. This article demonstrates the innovation work in a buy-in unit that provides such an office service in a large textile company. The stages of design thinking are progressing as listening to stakeholders, grouping insights, generating ideas, editing prototypes and getting feedback from stakeholders. Creative trust is achieved by applying design thinking innovation methodologies with step by step with determined actions.
\end{abstract}

Keywords: Active participation, innovation, design thinking, routine jobs.

*ORCID Prof. Dr., Erzincan Binali Yıldırım Üniversitesi, İİBF, İktisat Bölümü, mustafa.akin@erzincan.edu.tr 


\section{Extended Abstract}

Systems where employees sit in a row position, turn their faces to the wall listen to the manager are not effective. Without mutual interaction and active practice, employees are unable to track what they have misunderstood, forgotten and confused. How is effective innovation redesigned in the most static, monotonous and prescriptive units in the offices. This study demonstrates how design thinking in a strict prescriptive office system is redesigned through innovation. In this process, it is witnessed that the interaction between the manager and the employee has increased, that the employees have become a dynamic element from being a passive subject to an action-oriented system has been started. In the innovation methodology of design thinking that enables change, it is aimed to increase employee's selfconfidence by striving from memorization and knowledge portrayal and doing things step by step.

Innovation and entrepreneurship are based on abstract concepts such as creativity and thinking. Knowledge can be partly taught by heart, but creativity cannot be memorized. It cannot be evaluated with classical performance methods. In the classical performance approach, it is aimed to achieve visible targets within certain time (i.e., quarterly base).

It is difficult to go to practices that are opposite to the conventional memorization of knowledge and classical performance approach at the usual office services. However, every human being is born as a creator. Social institutions blind people. First of all, it is necessary to show that there is a field where everyone can contribute to innovation. Innovation is not to invent a great technology but to make a difference with added value.

In order to learn the systematic of the employees in the innovation process, they need to learn practically. An example carried out with a buy-in team at a large textile company is explained in detail.

The first stage in the design thinking is to obtain information by interviewing stakeholders. Stakeholders in the import purchasing unit were identified:

- Customs brokers

- Customs customer representatives

- Customs clearance experts

- Customs clearance manager

- Assistant customs experts

- Designers

- Design assistants

- Buying manager

- Buying assistants

- Foreign trade project experts

- Foreign trade project managers

- Import managers

According to insights obtained it is recognized that designers are not aware of G.T.I.P. system, carrying product information. The problem is that the container coming to the customs is not visible, and in the event of an inspection, the container and the data (G.T.I.P) sheets should match, otherwise, severe penalties occur. In the prototyping phase, it focuses on the reference guidance that show to designers how to fill the technical data sheet based on their textile model. 


\section{Giriş}

İnovasyon sürecinin bir parçası olmadığını düşünen rutin işlerin takipçisi olan arka destek (muhasebe, sekreterlik, satın alım gibi) birimlerinde inovasyon yapılabilir mi? Halbuki, organizasyon vizyonundaki inovasyonun sadece AR\&GE'nin değil, her birimin sorumluluğunda olan bir süreç olarak kabul edildiğinde toplu ve entegre değisşim ve başarı mümkündür. Organizasyon yapısı içinde inovasyona uzak gibi görünen, statik, monoton arka planda ofis hizmeti sunan birimler dahi inovasyonun kaynağı olabilmektedir. Bu makale de hem rutin işlerin inovasyon sürecinde katılımı hem de büyük bir tekstil firmasında rutin ofis hizmeti sunan ithalat satın alma (buy-in) biriminde gerçekleştirilen inovasyon çalışmasıdır.

Şirketlerdeki yanlış organizasyon yapılarından dolayı inovatif ürünler çıkartılamamaktadır. Kapalı ürün geliştirme kültüründe, sadece AR\&GE birimi yeni ürün geliştirmekten sorumludur (Şekil 1). Yeni ürün piyasasındaki ilk kötü sonuçlara karş1, AR\&GE birimi gerçeği inkâr yolunu tercih etmektedir. Çünkü piyasadaki kötü gidişat birime karşı bir tehdit oluşturmaktadır. Gelecekte birimin inanılırlığına daha da zarar verecek olsa da kendini kollamak için sürekli olarak abartılı tahmin raporları yayınlamaktadır. Operasyon birimi satışları ve kârlılığı arttırma telaşıyla fiyatları ve maliyetleri düşürmeye çalışmaktadır. Bir taraftan piyasa şartları ürünü yeniden tasarlamaya zorlarken hızlı sonuç alma telaşı şirketi "kısa dönemli” düşünmeye itmektedir. Baskı altındaki 'operasyon birimi' zaman kaybetmemek için başka bir ürün tasarlatmak yerine mevcut ürüne yama yapmayla krizi geçiştirmektedir. Bunun sonucunda satışlar düşmekte ve değerli zamanını pozisyonu sağlamlaştırmak adına boşa harcamaktadır. Bu kısır döngü devam etmektedir (Şekil 1).

Şekil 1: AR\&GE Merkezli Ürün Geliştirmede Başarısızlık Sebepleri

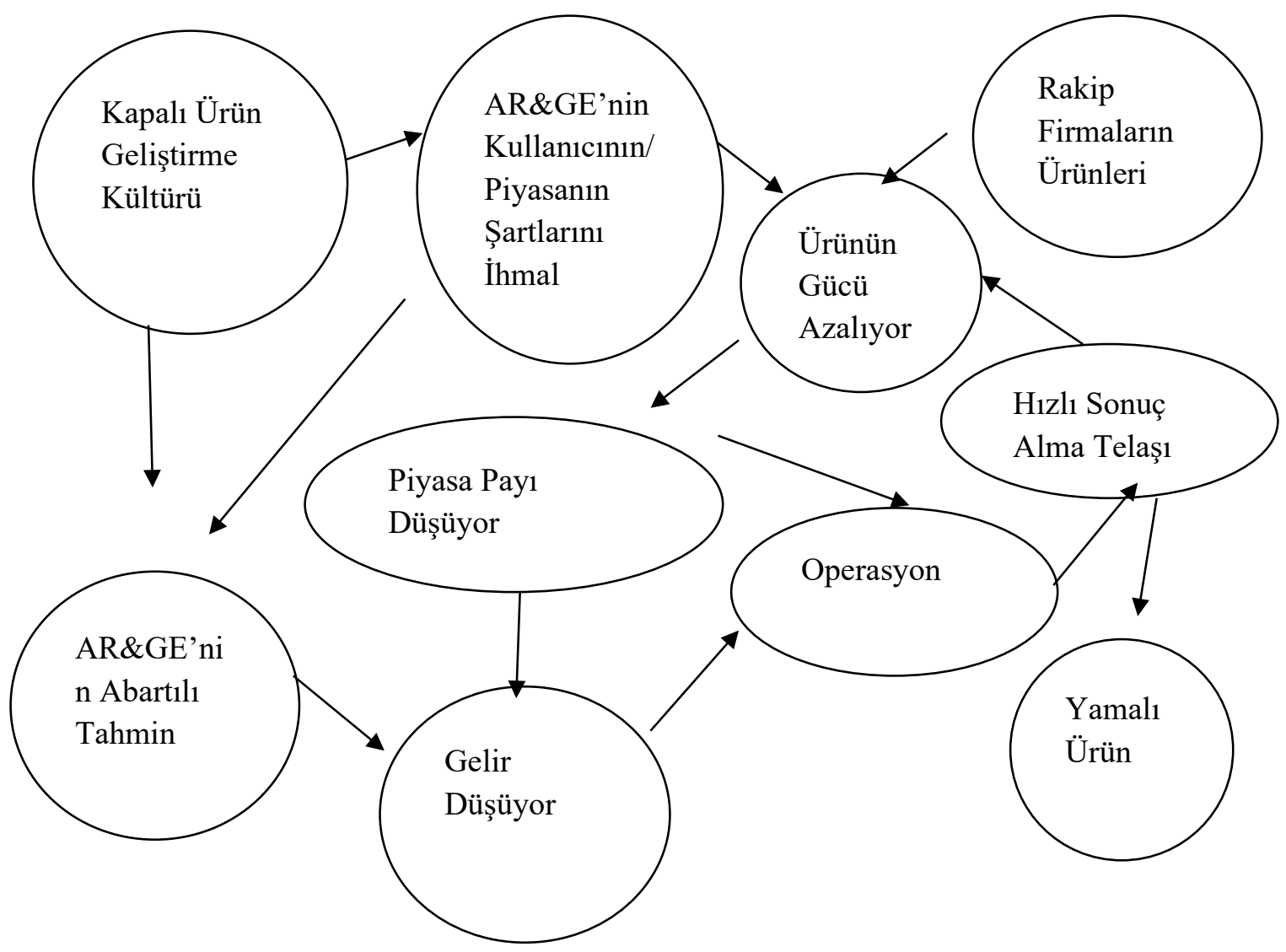

Kaynak: Kumar, 2012. 


\subsection{Ofis Sistemi}

Çalışanların saf halinde oturup yüzlerini duvara çevirdikleri ve yöneticinin konuşup çalışanların dinlediği sistemler etkin değildir. Karşılıklı etkileşim ve aktif uygulama olmadığı zaman çalışanların süreci ve içeriği anlamadıkları, unuttukları ve karıştırdıkları görülmektedir (Thornburg, 2012, s.34). Bu çalışma katı kuralcı ofis sisteminde tasarım düşüncesi inovasyon çalışmasıyla nasıl yeniden tasarlandığını göstermektedir (Thornburg, 2012, s.34). Bu süreçte yönetici-çalışan arasındaki etkileşimin arttığına, çalışanların pasif süje olmaktan dinamik bir unsur haline geldiğine ve aksiyon odaklı bir sisteme geçildiğine şahit olunmaktadır. Değişimi sağlayan tasarım düşüncesi inovasyon metodolojisinde, ezbercilikten ve bilgi hamallığından sıyrılıp çalışanın adım adım bir şeyler yaparak özgüveninin artması amaçlanmaktadır (Kelley ve Kelley, 2014, s. 56-98).

İnovasyon ve girişimciliğin öğretilmesinin zorluğu, temelinde yaratıcılık, düşünme gibi soyut kavramların olmasından ileri gelmektedir. Bilgiler, bir nebzeye kadar ezberle öğretilebilmekte ama yaratıcılık ezberletilemez. Klasik performans yöntemleriyle değerlendirmeye tabi tutulamaz. Yönetim klasik performans yaklaşımında belli zaman (üçer aylık veya yıllık) zarfında gözle görülür hedeflenmektedir.

Ofis hizmetlerinde olağan gelen ezber bilgi ve klasik performans yaklaşımının zıttı uygulamalara gitmek zordur (Pink, 2006, s.107). Hâlbuki, her insan yaratıcı doğmaktadır. Ama toplumsal kurumlar kişileri köreltmektedir (Robinson, 2011). Önce inovasyonun herkesin katk1 yapacağı bir saha olduğunu göstermek gerekmektedir. İnovasyon büyük bir teknoloji icat etmek değil katma değeri olan farklılık yaratmaktır (Drucker, 2007, s.105).

Çalışanların inovasyon sürecindeki sistematiğini anlayabilmesi için uygulamalı olarak öğrenmesi gerekmektedir. Büyük bir tekstil firmasında ithalat satın alma biriminin (buy-in) ekibiyle gerçekleştirilen çalışma detaylı olarak anlatılmaktadır.

\section{AR\&GE, Ekonomik ve İnsan Odaklı (Tasarım Düşüncesi) İnovasyon}

İnovasyonu üç farklı kaynakta aramak mümkündür: Mühendislik/ AR\&GE, ekonomik firsatlar ve insan odaklı (tasarım düşüncesi).

AR\&GE mühendislik alanında gerçekleştirilen teknik bir inovasyondur. AR\&GE harcamalarıyla finanse edilen ve AR\&GE laboratuvarlarında çalışan mühendisler tarafından geliştirilen teknolojidir. Örneğin daha hafif ayakkabı üretmek gibi bilinen ve tanımlı sorunların çözümünde işe yaramaktadır.

Ekonomi alanında ise inovasyon iş sektöründe bir fırsat yakalamaktır. Bir ihtiyacın piyasada karşılanmadığının görülmesi üzerine piyasaya bu ürünün sunulmasıdır. Örneğin fastfood endüstrisinin gelişimi ekonomik alandaki iş inovasyondur. Fast food restoranları klasik yeme anlayışına alternatif yeni bir değer önermesi getirmektedir.

Tasarım düşüncesi (insan odaklı inovasyon) rutin işler de dahil tüm birimlerden inovasyon kapısını açmaktadır. Tasarım düşüncesi bilinmeyen ve tanımsız sorunları sahada paydaşlardan anlama ve ekiple çözme sürecidir (Kelley, 2005: s. 88 ve Pink, 2006: s. 34). Tasarım düşüncesinde inovasyon yaratıcılıktan çok bir disiplin işidir (Brown, 2008: 45). Bir sonraki bölümde detaylı olarak yöntem anlatılmaktadır. 


\subsection{Tasarım Düşüncesinin Özellikleri}

Tasarım düşüncesi bir problem-çözüm sistemi olarak kullanıcı odaklı, ekip çalışmasına dayanan, inovasyon fırsatlarını yakalamaya çalışan deneme-yanılma yöntemidir (Brown ve Martin, 2015; Brown, 2009: s. 67; Kelley, 200: s. 110; Dorst, 2011, s: 33; Liedtka ve Ogilvie, 2011: s. 201; Luma, 2014: s. 45, Liedtka vb., 2014: s. 33).

Tasarım düşüncesinin özellikleri aşağıda sıralanmıştır:

Tasarım düşüncesi kullanıcı odaklıdır (Kelley ve Litman, 2001, s.15). Kullanıcılar kimler? Sadece demografik olarak değil, motivasyonları ve davranışları nelerdir? Kullanıcı odaklı bir organizasyon müşterilerini tanıyabilir, anlayabilir, ifade edilen ihtiyaçları dinleyebilir, ifade edilmemiş olanları tahmin edebilir ve onlar için üstün müşteri deneyimleri sunabilir. Kullanıcıları anlamak için "etnografik mülakat" ve "kendimizi yerine koyma" gibi araçlara ihtiyaç var. Bu metotlarda, müşteriye deneyimleri anlattırılmakta ve müşteri gibi davranılmakta. Örneğin bir çağrı merkezindeki etkinliği anlamak için, müşteri hattı aranmaktadır. Ne kadar beklenecek? Ne sıklıkla aktarılmakta? Doğru olan yanıtlar alınmakta mıdır? Böylece, kullanıcıların deneyimlerinin nasıl olduğunu anlaşılabilir ve empati kurulabilir.

Tasarım düşüncesi kullanıcıların hayatlarını daha iyi yaşamasına yardımcı olacak fursatlar bulmakla ilgilidir (Tscimmel, 2017, s. 75). Bir girişimci kullanıcıların karşılaştıkları acı noktaları ve gizli ihtiyaçları firsat olarak düşünürse; insanları, teknolojileri, fikirleri bir araya getirilebilir. Tasarım düşüncesindeki etnografik çalışmalar yoluyla kullanıcıdan derin içgörüler alınmaktadır. Beyin firtınası yeni fikirler üretmektedir. Prototipleme, zaman harcamadan yeni fikirlerin nasıl uygulanacağı konusunda rehberlik etmektedir (Beckman ve Barry, 2007, s. 35).

Tasarım düşüncesi yinelemeli bir süreçtir (Kumar, 2012, s. 19). Hipotezleri sürekli olarak test etmekte ve bulgulara göre değiştirmektedir. Minimum zaman ve para yatırımı ile başlamakta, zaman içinde kaynakları ayırmaktadır.

Tasarım düşüncesinin diğer inovasyon yöntemlerden temel farkı, insan odaklı olması ve çeşitli temellerden gelen ekiplerin beraber çalışmasıdır (Lietdka, 2018, s: 32; Tschimmel, 2012, s.23). Bu nedenle tasarım düşüncesi, insan merkezli tasarım olarak da adlandırılır. Ekipteki çeşitlilik, tasarım düşüncesi ilkeleriyle çalışan farklı deneyimlere ve eğitimlere sahip kişilerin beraberliğini göstermektedir. Tasarım düşüncesi, kullanıcılarla empati kurmakla ilgilidir. Birey duygularla düşünür ve hareket eder. Öncelikle işlevsel olmaktan ziyade duygusal gelişmeler hedeflenmektedir.

Pazar araştırmasına kıyasla tasarım düşüncesinde benzersiz olan, araştırmanın amacının beklentisiz olmasıdır. Tasarım düşüncesinde ne inşa edileceği, belirli bir ürün veya pazar yoktur. Bunun yerine kullanıcıya ve firsatlara odaklanılır: bir ihtiyacı keşfederek yeni pazarlar keşfedilmektedir (Kim ve Mauborgne, 2004, s. 90)

Ekonomimizde, otomobiller, uçaklar, tatiller, evler ve telefonlarda fonksiyonel ihtiyaçlar karşılanmaktadır. İnsanlar bu aletleri örneğin uçağı uçmak için kullanmazlar. Arkadaşlarıyla buluşarak özel zamanları geçirmek için bir turistik seyahatte bulunmak isterler (Pine ve Gilmore, 2011, s. 88). Kullanıcıların hayatlarını (statü, beklentiler, duygular, aktiviteler, bağlantılar) öğrendikten sonra inovasyon için sınırsız bir alan vardır.

\subsection{Tasarım Düşüncesi}

Süreç dört aşamalı olarak ifade edilmektedir: görmek, anlamak, yapmak ve test etmek. Görmekten amaç, insanların tecrübelerini gözlemlemek, anlamaktan zorlukları ve firsatları 
analiz etmek, yapmaktan gelecekteki olasılıkları görselleştirmek ve test etmekten sürekli geri bildirim elde etmektir (Liedtka ve Ogivie, 2011: s.23; Brown, 2008: s. 56, Kelley, 2002: 32; Kelley ve Kelley,2013: s.65; Kumar, 2012: s.49).

İlk adım görmektir. Kullanıcılarla empati kurulmaya çalışılmaktadır (Luma Institute, 2012: s.39, Standford Design School, 2009: s.34, 2014). Bu aşamada durum, sorun, konu, insanlar, ilişkiler, hedefler ve tarihsel gelişimler araştırılmaktadır.

İkinci aşama anlamaktır (Luma Institute, 2012: s. 77). Bu bölümde toplanan veriler incelenmektedir. Genel eğilimleri ve iç görüleri gruplandırılmaktadır. Sorunun kaynaklarını anlama amacıyla sebep-sonuç analizleri yapılmaktadır.

Üçüncü aşama, yapmada, elle tutulabilir bir çözümün canlandırılmasıdır. Çözümün anlaşılabilir ve değerlendirilebilir olması için kelimelerden mümkün olduğunca kaçınıp görsel prototip yapmak gerekir. Görsellik bir video, maket, senaryo veya eskiz olabilmektedir. Önemli olan kullanıcının prototipi algılayabilmesi ve yorum yapabilmesidir (Luma, 2014, s.54).

Dördüncü aşamada, deneme-yanılmayla prototipler kullanıcıların testine tabi tutulmaktadır (Steinbeck, 2011: s.45). Test aşamasında kullanıcılar gördükleri veya dokundukları prototipler üzerinden yorum yapmaktalar.

Tasarım düşüncesi kullanıcıların faaliyetlerine odaklanmakta ve faaliyetleri ilerletmeye yönelik ürün sunmaktadır (Brown, 2008: s. 48, 2009: s.91). Kullanıcının deneyimini ve hissini ön planda tutmaktadır.

Paydaşlarla görüşülerek sürekli olarak geri bildirimlerle "değer önerileri”" yenilenmektedir. Ürünlerin geliştirilmesi tahminlere dayalı olmak yerine kullanıcılardan ve paydaşlardan elde edilen geri bildirimlerle olmaktadır (Liedtka,ve Ogilvie 2011: s.100; Liedtka vd., 2014: s.62, Luma, 2014: s.82).

Tasarım düşüncesi sorun çözme sürecini tasarımcılardan almıştır (Kelley, 2005: s. 93; Brown, 2009: s. 59). Tasarımcıların bir nesneyi yaratmak veya ilerletmek için kullandıkları araçlar ve bakış açıları süzülmüştür. Örneğin bir mobilya veya takı için kullanılan süreç bir kamu sağlık servisinin veya organizasyon şemasının yeniden inşa edilmesi için kullanılmaya başlanmıştır (Kelley ve Kelley, 2013: s.68; Kumar, 2012: s.15; Brown, 2009: s. 59). Bir kurumda tasarım düşüncesi benimsediğinde, çalışanlar problemi tanımlama, firsatları keşfetme ve belirsizlikte iz bulma yöntemlerini içselleştirmektedir (Nelson ve Stolterman, 2012: s.45; Nixon, 2013: s. 88).

Geleneksel iş disiplinleri operasyonel etkinlik ve bilimsel araştırma varsayımlarla ilerlerken, tasarım düşüncesi kullanıcı odakl, ekip çalışmalı, empati esaslı ve prototiplerle ilerlemektedir (Denzin ve Lincoln, 2005: 90).

\section{Sürecin İşletilmesi}

Bu çalışmada tasarım düşüncesinde Şekil 2'deki yöntemler kullanarak ilerlenmektedir: Görmek aşamasında mülakat yapılmakta, anlama aşamasında çıkarımlar gruplanmakta ve beyin firtınasıyla çözümler üretilmekte, yapmak aşamasında prototip olarak kılavuz rehber oluşturulmakta ve test etmede sesli eleştiri getirilmektedir. 
Şekil 2: Tasarım Düşüncesi Sürecin Kurgulanması

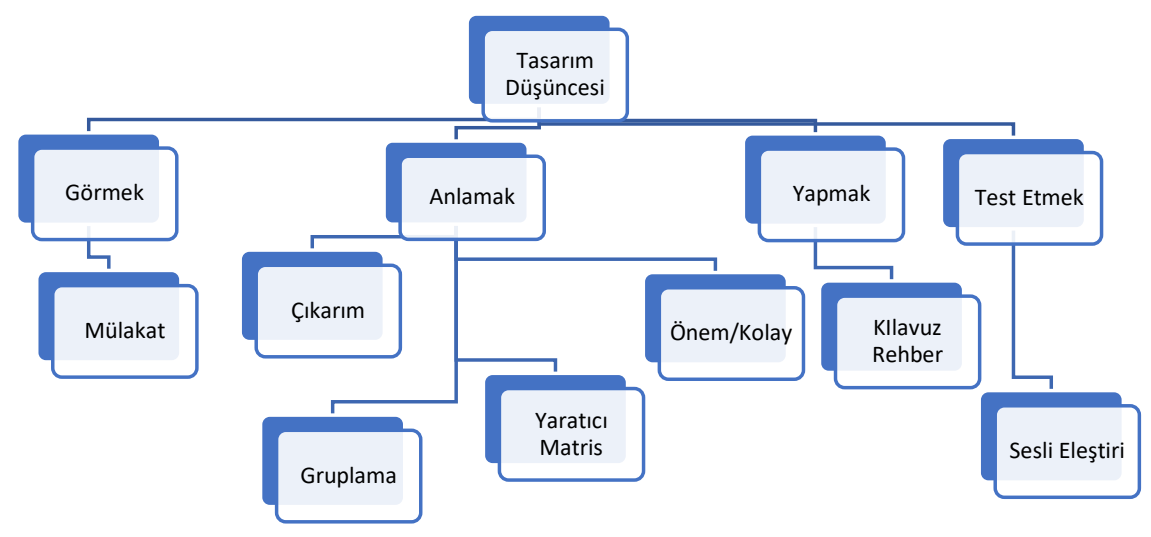

Kaynakça: Luma Institute (2014)

\subsection{Görme tekniği: Mülakat}

Tasarım düşüncesinde birinci aşamada paydaşlarla mülakatla bilgi edinmek vardır. İthal satın alma birimindeki paydaşlar belirlenmektedir:

- Gümrük müşavirleri

- Gümrük müşteri temsilcileri

- Gümrükleme uzmanları

• Gümrükleme yöneticisi

- Gümrük uzman yardımcıları

- Tasarımcilar

- Tasarım asistanları

-Satın alma müdürü

- Satın alma asistanı

- Dış ticaret proje uzmanları

- Dış ticaret proje yöneticileri

•İthalat müdürleri

$\mathrm{Bu}$ uzmanlarla mülakatlarda sorunları ve kaynakları araştırılmaktadır. Görüşürken empati kurulmakta, paydaşların çözüm önerileri, talepleri, istek ve beklentileri de öğrenilmektedir (Liedtka,ve Ogilvie 2011: s.10; Liedtka vd., 2014: s.16, Luma, 2014: s.18). 


\subsection{Anlama: Çıkarım ve Gruplama}

İkinci aşama olan anlama aşamasında elde edilen bilgiler doğrultusunda tasarımcıların ve grafikerlerin G.T.I.P. sisteminden farkında olmadıkları ortaya çıkmaktadır.

Teknik föylerde her ürünün uluslararası geçerliliği olan gümrükleme G.T.İ.P. numarası mevcuttur (6210.20.00.0018 gibi) (Emek, 2017). Bu numaralar sisteme girildiğinde ürünün tanımı çıkmaktadır.

Vergilendirme, KDV hesaplamaları, ek mali yükümlülükler bu tanımlara göre verilmektedir. Yanlış bir beyanda bulunulduğunda kaçakçı ya da usulsüz işlem yapan firma durumuna düşülmektedir (Gümrük Vergi Kanunu, 2019: 234. madde).

Tekstil firmasındaki uygulama şu süreci takip etmektedir: tasarımcı ürünü tasarlamakta, grafiker çizimi yapmakta ve kumaş detaylarını sisteme girmekte, satın alma ekibi de kontrol etmekte ve onay vermektedir. Bu veri girişlerinin sonucunda sistemde teknik föy oluşmaktadır (tablo 1, şekil 3 ve 4). Ürünler gümrüğe geldiğinde de ithalat işlemlerine başlamak üzere gümrükleme ekibi devreye girmektedir.

Tablo 1: Teknik Föy

\begin{tabular}{|l|l|}
\hline P.O. & 235272 \\
\hline Model & Heyda \\
\hline Cinsiyet & Erkek \\
\hline Ürün grubu & Uzun kol, gömlek, ekose dokuma. \\
\hline Kumaş & $\% 40$ pamuk, \%60 Viskas \\
\hline Etiket kumaş bilgisi & $\% 40$ pamuk, \%60 Viskas \\
\hline
\end{tabular}

Şekil 3: Gömlek

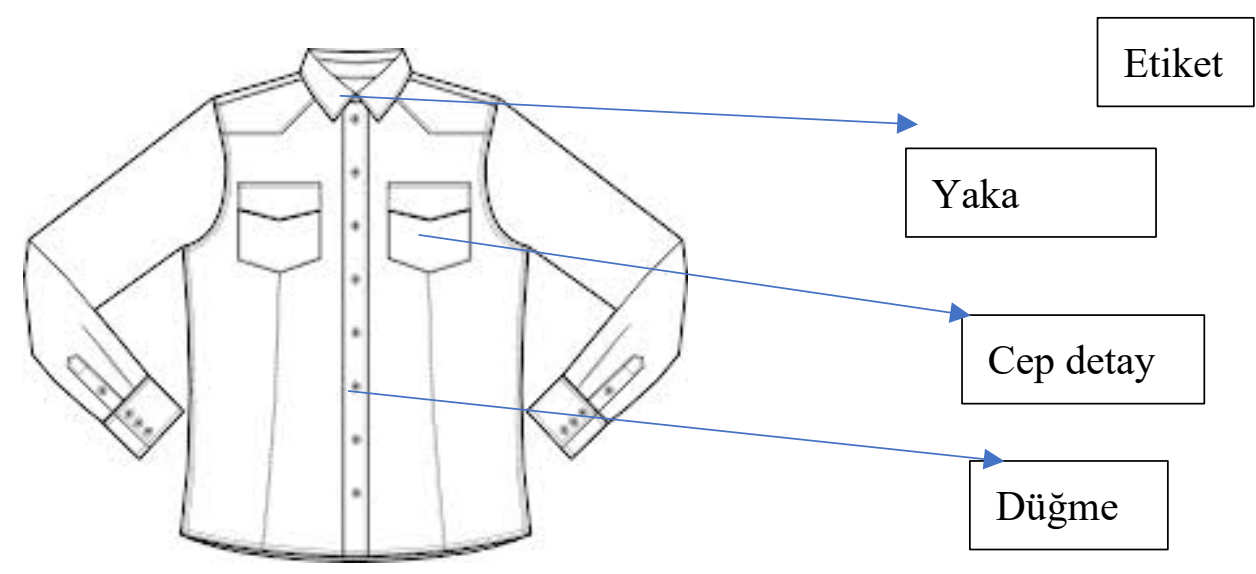


Şekil 4: Kumaş Bilgisi

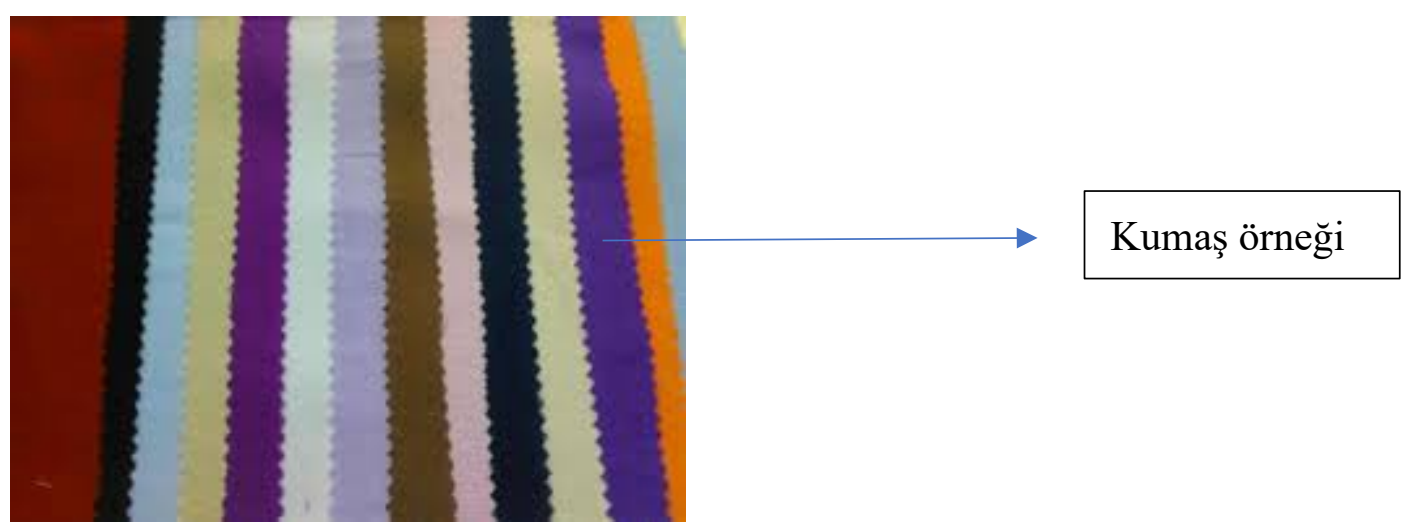

Bu teknik föydeki detaylara bakarak buy-in birimi ürüne ait G.T.I.P. numarası vermekte ve ürün beyannamesine ait vergiler buna göre belirlenmektedir. G.T.İ.P. numarası kumaş türü, cinsiyet, hammadde, eşyanın nevi, örme, dokuma gibi detaylara göre değişmektedir. Sorun şu ki: gümrüğe gelen konteynerin içi görülmediğinden, teknik föylerde hatalı veri girişi yapıldığında ani bir denetimde, konteynerin içinden farklı bir ürün çıkarsa ağır cezai durumlar oluşmaktadır (Gümrük Vergi Kanunu, 2019).

\subsection{Beyin Fırtınasında Yaratıcı Matris ve Önem/Kolay Matrisi}

\section{Resim 1: Yaratıc1 Matris}

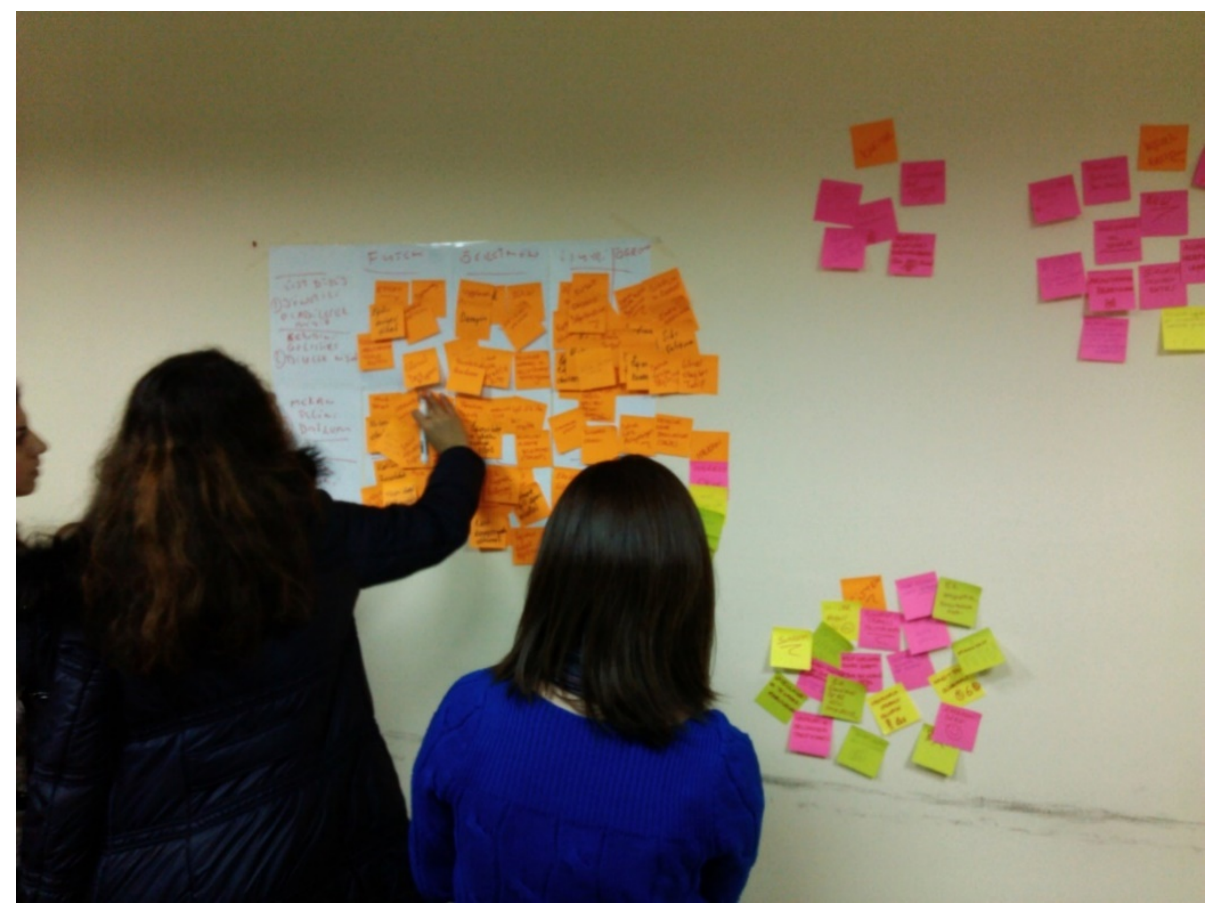

Kaynak: Akın, 2019

G.T.İ.P.'de uyumsuzluk problemi anlaşıldıktan sonra, beyin firtınası yöntemiyle birçok fikir üretilmektedir (Resim 1). Beyin fırtınası yöntemlerinden yaratıcı matriste birçok fikir 
üretilmesine destek olmaktadır. Satır bölümüne sorular yazılmaktadır Sütuna ise eldeki çözüm kaynakları belirlenmektedir; insan kaynakları, iletişim, teknoloji gibi.

Resim 2: Önem /Kolaylık Matrisi

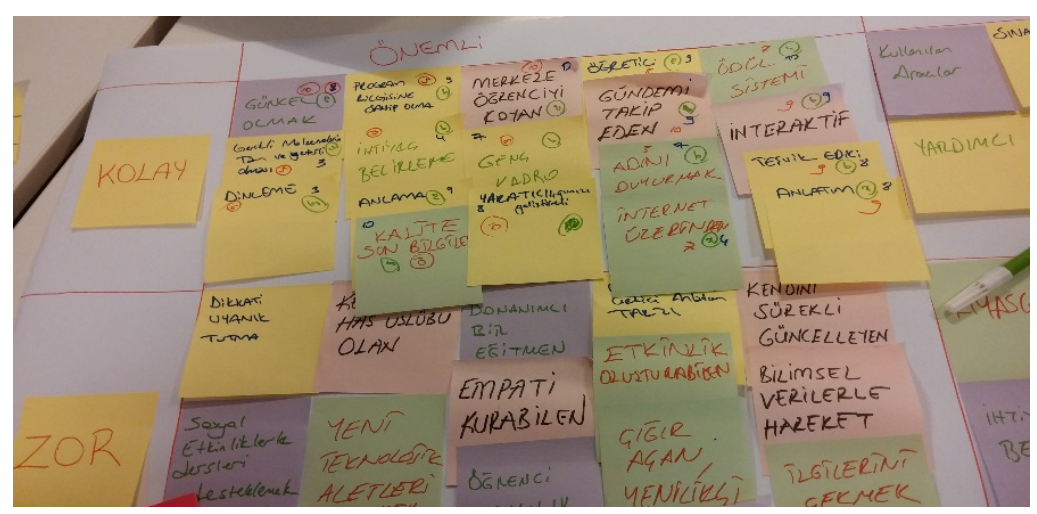

Kaynak: Luma, 2014

Birçok fikir arasında seçim içinde önem/kolay matris yöntemi en iyi fikirlere öncelik verilmesini sağlamaktadır. Fikirlerin önemlilik ve kolaylık sıralamasında yerleştirilmesi istenmektedir (resim 2).

Zorluk; zaman, kültürel veya maliyet olabilmektedir. Burada amaç, fikirleri hızlı şekilde önem sırasına göre düzenlemek, aksiyon planını kolayca harekete geçirmektir. Özellikle önemli ve kolay kesişen hücre arzu edilen düzlemdir. Önemli olmayan ama zor olanı gerçekleştirmek lüks bir çabadır. Zor ve önemli hücre ise uzun vadede stratejiyi kapsamaktadır.

\subsection{Kılavuz Rehber ve Sesli Eleştiri}

Teknik föyü tasarımcıların ve grafikerlerin anlayabilecekleri şeklinde tekrar tasarlanma ve bunun üzerine bir atölye çalışması fikri üzerinde durulmaktadır. Atölye çalışmasının içeriği kılavuz rehberle anlatılmaktadır. Bir televizyonun kullanımının anlatıldığ gibi, dersin içeriklerinin madde madde anlatılmasını kapsayan bir rehberdir (Luma, 2014: s.100).

Ders tasarımcılara ve grafikerlere verildikten sonra, artık tasarımcılar ve grafikerler uygun G.T.İ.P numaralarını girmektedirler. Böylece milyonlarca liralık yanlış beyannameden dolayı zararın önüne geçilmektedir.

\section{Sonuç}

Tasarım düşüncesi modeliyle beraber, tek inovasyon sorumlusu birim olan A\&Ge'nin dışına çıkıp, tüm birimleri içeren süreç geliştirilmiştir. İnovatif olamayacağı düşünülen ofis hizmetlerinde tasarım düşüncesi metolojisinin uygulamasıyla dönüşüm gerçekleştirilmiştir.

Tasarım düşüncesindeki aşamaları tanıma (görme), sistemleştirme (anlama), taslak üretme (yapmak) ve uygulama (test etmek) olarak ifade edilmektedir (Brown ve Wyatt, 2010, s.109). Sürecin başında paydaşlarla birlikte gerçek problemin araştırılması ve tanımlanması gerekmektedir. Sorunun kökeni sahada görülmelidir. Daha sonra çıkarımlar arasında birbirleriyle benzeş gruplamalar (sistemler) oluşturularak kavramlaştırılmakta ve çözümler (prototipler) üretilmektedir (Kelley ve Littman, 2001: s.45). 
Örnek uygulamada bir tekstil firmasının dış ticaret buy-in biriminde çeşitli kademelerde çalışanlarla tasarım düşüncesi kullanılarak gerçekleştirilen inovasyon süreci aktarılmaktadır. Ofis hizmetlerinin kuralcı, bürokratik ve tek düze yapısının inovasyona izin vermediği zannedilmektedir. Her ekosisteminin bir kısitlaması olacaktır. Bütün bu kısitlamalar göz önünde bulundurularak sorun tanımlanmakta ve çözüm aranmaktadır. Sürecin başında, buy-in birimiyle ilgili paydaşlarla mülakat yapılmakta ve sahada çalışanların gözünden sorunlar tespit edilmektedir. Önerilen çözüm olan GTIP numaralarının nasıl kullanılacağı bir kılavuz rehber halinde prototipleştirilmektedir.

Çalışanları inovasyona zorlamak bir konuda bilgisi olmayana o işi yaptırmaya benzemektedir. Yaratıcı ol, bakış açını değiştir gibi yaklaşımlar çalışanlarda özgüven erimesine yol açmaktadır. Tasarım düşüncesinin geliştirilmesiyle beraber, inovasyon da artık bir disiplindir. Takip edilmesi gereken bir metodoloji vardır. Çalışanın önce ekip halinde konunun paydaşlarıyla görüşüp, sorun hakkında etraflıca bilgi sahibi olduktan ve bu çıkarımlar da bir sistem çerçevesinde gruplandırıldıktan sonra beyin firtınasına geçilebilmektedir. Üretilen çözümler görselleştirilip tekrar kullanıcılardan geri bildirim alınarak süreçteki döngü beslenmektedir.

\section{Kaynakça}

Akın, M.Ş. (2019). Farklı Bakış Açısı Kazanmak İçin Beyin Fırtınası Modelleri, Süleyman Demirel Üniversitesi Vizyoner Dergisi, 10, 23: 15-24.

Brown, T. \& Martin, R. (2015). "Design for Action", Harvard Business Review, 55-64

Brown, T. \& Wyatt, J. (2010). "Design Thinking for Social Innovation”, Stanford Social Innovation Review.

Brown, T. (2008). "Design Thinking”, Harvard Business Review, 25 (6):123-132.

Brown, T. (2009). Change by Design: How Design Thinking Transforms Organizations and Inspires Innovation, Harper Business, New York.

Dorst, K. (2011). “The Core Of 'Design Thinking' And Its Application”, Design Studies, 32, 6: $521-532$.

Emek, F. (2023). Gümrük Tarife İstatistik Pozisyonu (GTİP) Nedir? https://www.eritela.com/ gumruk-tarife-istatistik-pozisyonu-gtip-nedir/

Gümrük Vergisi Kanunu (2019). Yanlış İthalat Beyanından Alınan Ceza. https://www.mazars.com.tr/Anasayfa/Blog/Makaleler/Ithalatta-Alinan-KDV-de-CezaUygulamasi

http://www.youtube.com/watch?v=-FzFk3E5nxM

Kelley, T \& Littman, J. (2001). The Art of Innovation: Lessons in Creativity from IDEO, America's Leading Design Firm Crown Business, Crown Business, New York.

Kelley, T. \& Kelly, D. (2014). Yaratıcı Özgüven, Optimist Yayınları, İstanbul.

Kelley, T. (2005). The Ten Faces of Innovation, Doubleday, New York.

Kelley, T., \& Littman, J. (2001), The Art of Innovation: Lessons in Creativity from IDEO, America's Leading Design Firm Crown Business. Crown Business, New York.

Kim, C. W. \& Mauborgne, R. (2004). Blue Ocean Strategy. Harvard Business School Press.

Kumar, V. (2012). 101 Design Methods: A Structured Approach for Driving Innovation in Your Organization, Wiley, Chicago:

Liedtka J \& Ogilvie, T. (2011). Designing for Growth, Columbia Business School, New York. Liedtka, J. (2018). Why Design Thinking Works. Harvard Business Review, September

Liedtka, J., King, A. \& Bennett,K. (2014). Solving Problems with Design Thinking, Columbia Business School, New York. 
Luma Institute. (2012). Innovating for People Handbook of Human-Centered Design Methods, LUMA Institute, Chicago.

Luma Institute. (2014). "Innovation Taxonomy”, Harvard Business Review, 37 (1): 111-112

October.

Pine, J. \& Gilmore, J. (2011), The Experience Economy, Cambridge: Harvard Business Review Press.

Pink, D. (2006). A Whole New Mind, Riverhead Trade, New York.

Sara L. Beckman, C. \& Barry, M. (2007), Innovation as a Learning Process: Embedding Design Thinking. California Management Review, 50 (1), 25-49.

Standford Design School (2009). d.school bootcamp bootleg.

Stanford Design School (2014). Design Thinking Virtual Crash Course

Steinbeck, R. (2011). "Building Creative Competence in Globally Distributed Courses Through Design Thinking”, Comunicar, 37 (19): 27-35.

Tschimmel, K (2017). Evolution 62 Innovation and Design Thinking Model. Mindshake, Porto.

Tschimmel, K. (2012). Design Thinking as an Effective Toolkit for Innovation. In: Proceedings of the XXIII ISPIM Conference: Action for Innovation: Innovating from Experience. Barcelona. 